\title{
Bromide sources and loads in Swiss surface waters and their relevance for bromate formation during wastewater ozonation
}

\author{
Fabian Soltermann ${ }^{\mathrm{a}}$, Christian Abegglen ${ }^{\mathrm{b}}$, Christian Götz ${ }^{\mathrm{c}}$ and Urs von Gunten* ${ }^{\mathrm{a}, \mathrm{d}, \mathrm{e}}$ \\ ${ }^{a}$ Eawag, Swiss Federal Institute of Aquatic Science and Technology \\ CH-8600, Dübendorf, Switzerland \\ ${ }^{\mathrm{b}}$ ERZ Entsorgung + Recycling Zürich \\ CH-8050, Zürich, Switzerland \\ ${ }^{\mathrm{c}}$ Envilab \\ CH-4800, Zofingen, Switzerland \\ d Institute of Biogeochemistry and Pollutant Dynamics, ETH Zürich, \\ CH-8092, Zürich, Switzerland \\ e School of Architecture, Civil and Environmental Engineering (ENAC), \\ Ecole Polytechnique Fédérale de Lausanne (EPFL), \\ CH-1015 Lausanne, Switzerland.
}

\section{This PDF file includes:}

6 texts, 7 tables and 11 figures are available for further information addressing materials, experimental procedures and additional data.

*To whom correspondence should be addressed.

E-mail: vongunten@eawag.ch Phone: +41-58-765-5270Ｆax: +41-58-765-5210 


\section{A Criteria to upgrade WWTPs with ozone or PAC and WWTPs meeting the criteria}

\section{Text S1.}

Swiss authorities passed a new water protection law which foresees to mitigate the discharge of micropollutants to surface waters by upgrading more than 100 of the most impacting wastewater treatment plants (WWTPs) over the next 20 years. ${ }^{1}$ The criteria to upgrade WWTPs are given in a commentarial report to the changes in the Swiss regulation of water protection. ${ }^{2}$ WWTPs have to upgrade their treatment train with ozonation, powdered activated carbon (PAC) or other suitable processes to eliminate $80 \%$ of the micropollutants if they fullfill one of the criteria $1-4$ given by the Federal office of the Environment (FOEN):

1. WWTPs with $>80^{\prime} 000$ people in the catchment.

2. WWTPs with $>24^{\prime} 000$ people in the catchment and which are in the catchment of a lake.

3. WWTPs with $>8{ }^{\prime} 000$ people in the catchment and which discharge into a river with $>10 \%$ flow contribution of untreated wastewater (untreated refers to the elimination of micropollutants, hence the absence of a treatment with ozone or powdered activated carbon).

4. WWTPs with $>$ 8'000 people in the catchment and which discharge into a river with special hydrological properties (fast infiltration into drinking water sources), or WWTPs with $>1$ '000 people in the catchment and which discharge into an ecologically sensitive river, or one that is important for drinking water production with $>5 \%$ flow contribution of untreated wastewater (untreated refers to the elimination of micropollutants, hence the absence of a treatment with ozone or powdered activated carbon).

The selection of the WWTPs in the model of the main text is based on a study from 2012 which investigated the increase in costs and energy demand by upgrading about 100 WWTPs according to criteria $1-4 .^{3}$ In conclusion, 13, 69, 21 and 20 of the about 740 Swiss WWTPs are classified to the categories 1, 2, 3 and 4, respectively (WWTPs classified in categories 1-3 are shown in Figure S1). Investigations in this study refer to WWTPs fullfilling criteria 1-3 since criteria 4 is a weak criteria which requires interpretation by the cantonal authorities and concerns primarily small WWTPs.

\section{Test procedure to evaluate the treatability of wastewater with ozone}

A test procedure has been proposed to evaluate whether ozonation is an appropriate mean to reach the required micropollutant elimination of $80 \%$ in specific WWTPs. ${ }^{4}$ The procedure consists of 5 modules in which ozone stability (module 1), micropollutant elimination (module 2), oxidation by-product formation (module 3), ecotoxicological effects (module 4), and a pilot plant application (module 5) are tested. In conclusion, specific bromate formation during wastewater ozonation is investigated in module 3 . 


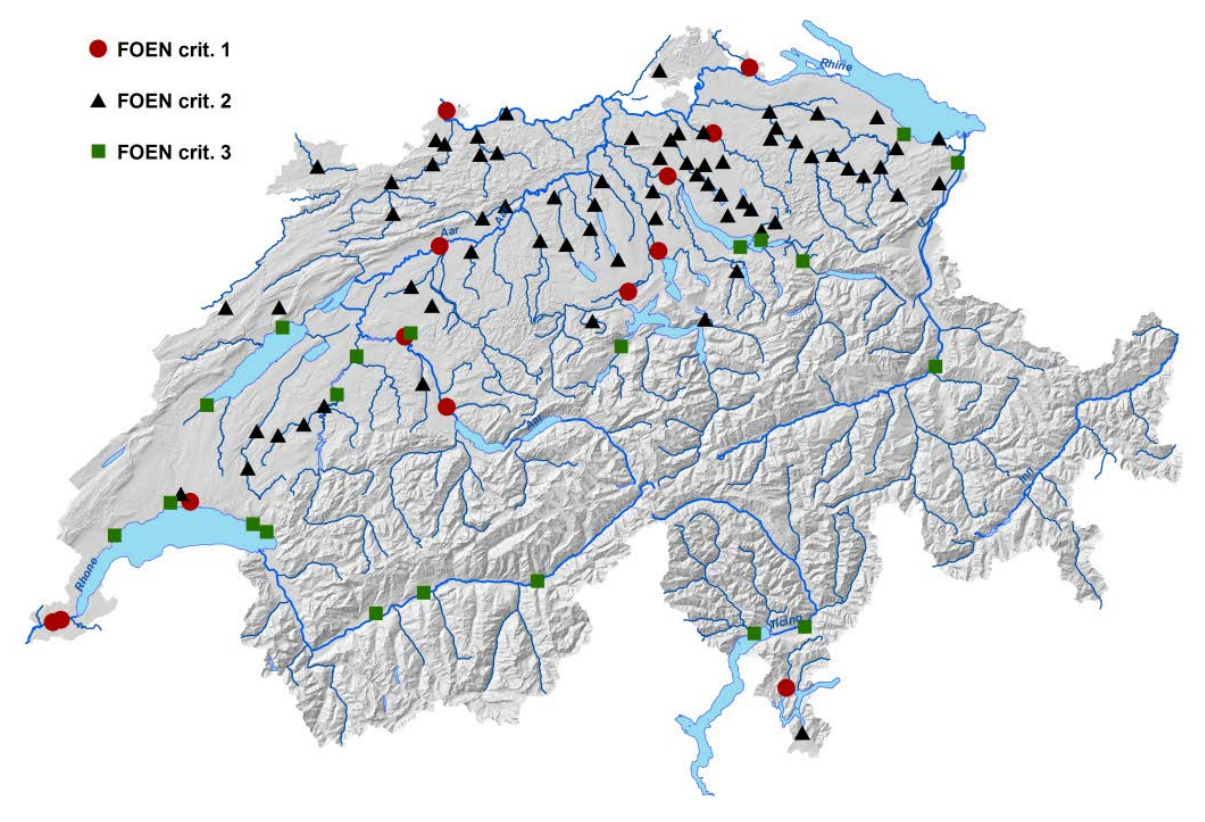

Figure S1: Map of WWTPs in Switzerland (2012) meeting FOEN criteria 1-3. Map reproduced with permission from (c) swisstopo, Wabern, Switzerland. 


\section{B Bromide concentrations in Swiss drinking water sources}

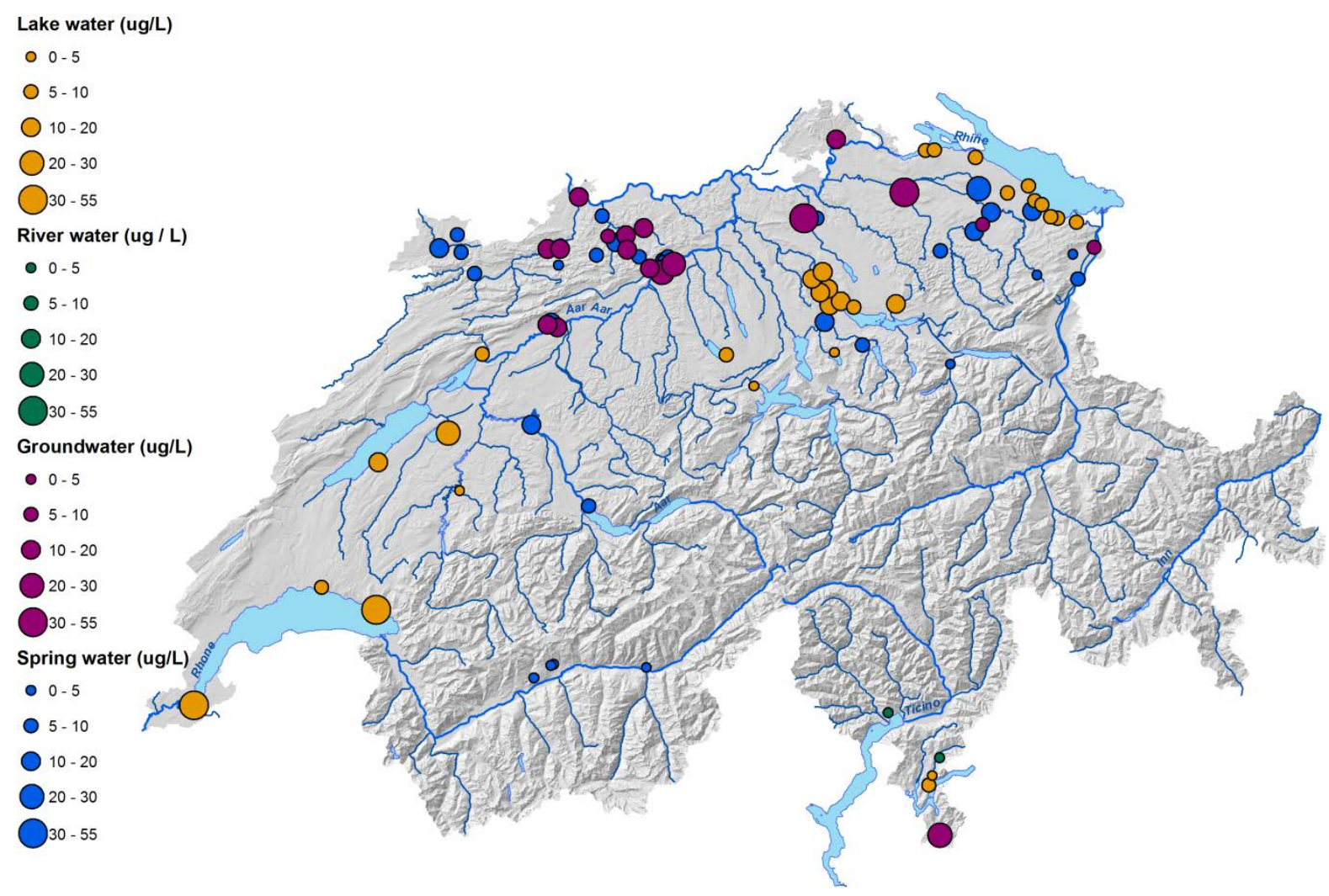

Figure S2: Bromide concentrations in water sources of Swiss drinking water treatment plants with an ozonation step (data from von Gunten and Salhi ${ }^{5}$ ). Surface and groundwater sources in urban and industrial areas commonly have higher bromide concentrations than rural spring waters or groundwaters. Map reproduced with permission from (c) swisstopo, Wabern, Switzerland. 


\section{Bromide and chloride concentrations in surface waters}
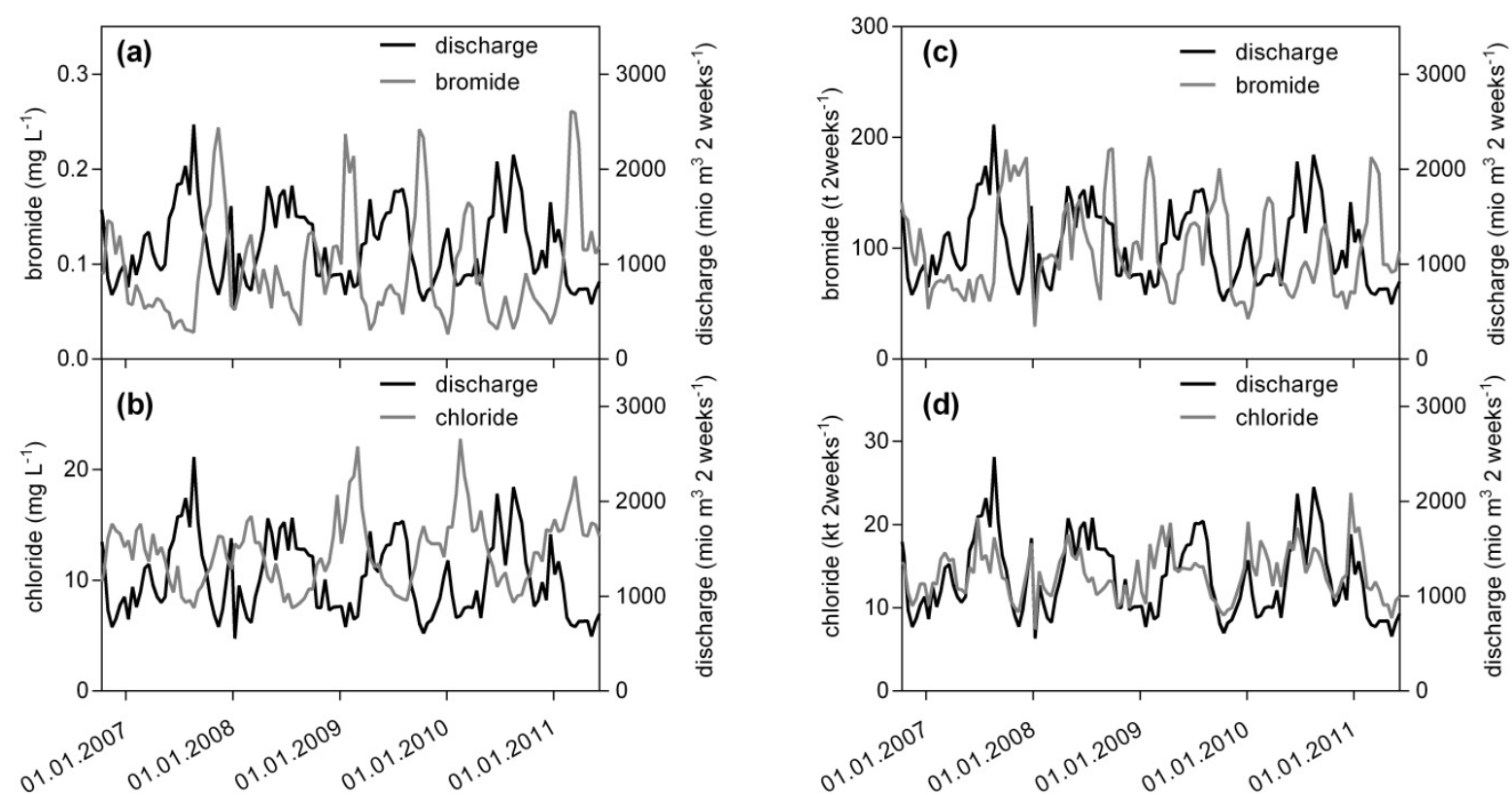

Figure S3: Discharge at the sampling point Weil am Rhein for biweekly composite samples with (a) bromide and (b) chloride concentrations and with (c) bromide and (d) chloride loads. Low discharge during winter results in higher bromide and chloride concentrations. The bromide and chloride loads show no clear seasonal trends although chloride loads seem to partly follow the discharge pattern. 


\section{Bromide sources in Switzerland}

\section{Text S2.}

Morf et al. (2002) provided a mass flow analysis of the most abundant BFRs (polybrominated diphenylethers (PBDEs) and tetrabromobisphenol A (TBBPA), which represented $\sim 2 / 3$ of BFRs used in Europe in $2001^{6}$ ) and concluded that Swiss waste contained $900 \mathrm{t} \mathrm{a}^{-1}$ of PBDEs and TBBPA in the late 90 s. $^{7}$ Thereof $65-85 \%$ was incinerated in municipal waste incinerators. ${ }^{7}$ If we assume an average bromine content of $\sim 70 \%(\mathrm{w} / \mathrm{w})$ for BFRs, $600-800 \mathrm{t} \mathrm{a}^{-1}$ of bromine from BFRs are incinerated in municipal waste incinerators. Morf et al. (2002) estimated that the use of BFRs increases annually by $5 \%{ }^{7}$ which would results in $~ 1100 \mathrm{t}$ of bromine incinerated in Swiss municipal waste incinerators in 2012.

We performed a mass flow analysis based on data of a Swiss waste survey in 2012 (Table S1) ${ }^{8}$ to estimate the bromide discharges to surface waters resulting from municipal waste incineration in Switzerland. The total amount of waste burnt in incinerators only changed marginally during the last years. ${ }^{8}$ The waste which was burnt in special waste incinerators (see main text) or cement mills is not included in this mass flow analysis. According to the associations of cement mills, the six cement mills in Switzerland burnt about 300'000 t of alternative fuel (such as waste oil, plastics, solvents, used wood, etc.) in 2012. ${ }^{9}$ Since Swiss cement mills do not use scrubbers to clean the exhaust gas, bromide is released to the atmosphere. This emitted bromide is considered in the mass balance of this study by taking into account bromide from precipitation.

For all municipal waste incinerators, an average bromine content of the waste was estimated according to measurements by Morf et al. ${ }^{10}$ (130 $\mathrm{mg}_{\text {bromine }} \mathrm{kg}_{\text {waste }}{ }^{-1}$ and $440 \mathrm{mg}_{\text {bromine }} \mathrm{kg}_{\text {waste }}{ }^{-1}$ for household and industrial waste, respectively). The average composition of Swiss waste in 2012 was taken from a survey by Steiger (2014), which revealed that $83 \%$ of the incinerated waste in Switzerland was household waste and $17 \%$ waste from industry and construction. ${ }^{11}$ In our mass balance, the bromine content of waste from industry and construction was set equal to the bromine content of industrial waste. Hence, the bromine content of Swiss waste was estimated to be $183 \mathrm{mg}_{\text {bromine }} \mathrm{kg}_{\text {waste }}{ }^{-1}(0.83 \times$ $130 \mathrm{mg}_{\text {bromine }} \mathrm{kg}_{\text {waste }}{ }^{-1}+0.17 \times 440 \mathrm{mg}_{\text {bromine }} \mathrm{kg}_{\text {waste }}{ }^{-1}$ ).

To calculate the bromide discharge to surface waters, we used data from Morf et al. ${ }^{10}$, which suggests that bromine from incinerated waste is transferred to $\sim 60 \%, \sim 35 \%$ and $\sim 5 \%$ as bromide to wastewater of the scrubber, to the fly ash and to the slag, respectively. Another study estimates that about $90 \%$ of the bromine is captured in the scrubber and $10 \%$ in the slag. ${ }^{12}$ Only 4 Swiss municipal waste incinerators do not treat their exhaust gas with scrubbers (Table S1). The average water use of a scrubber is estimated to be $0.22 t_{\text {water }} t_{\text {waste }}{ }^{-1} 13$, but can be up to 6 times higher depending on the technology in use and the operation. ${ }^{14}$ However, the water use of scrubbers mainly affects the bromine 
concentration in the wastewater of the municipal waste incinerator and only to a minor degree the bromine load.

Our mass flow analysis, based on the bromine content in Swiss waste and the measured bromine fate after incineration (see above), reveals that bromine concentrations in wastewater from municipal waste incinerators are about $800 \mathrm{mg} \mathrm{L}^{-1}$ and $500 \mathrm{mg} \mathrm{L}^{-1}$ for plants with scrubbers/fly ash washing and with scrubbers/without fly ash washing, respectively (Table S1). However, these concentrations are calculated with data on bromine content of Swiss waste in $2003 .{ }^{10}$ This is a rather conservative estimation since Morf et al. assumed that the use of BFRs increased annually by $5-7 \%{ }^{7}$

Figure S4 shows bromide and chloride concentrations of monthly composite samples measured in two Swiss municipal waste incinerators (No 1, No 2) during one year. Bromide concentrations were in the range of 200-800 $\mathrm{mg} \mathrm{L}^{-1}$ (chloride concentrations ranged from 25-50 $\mathrm{g} \mathrm{L}^{-1}$ ). Figure S5a shows bromide and chloride concentrations in the wastewater of another Swiss municipal waste incinerator (No 3) in daily composite samples from 2001 to 2014. Bromide concentrations in incinerator 3 werequite low before 2011 (50-100 $\mathrm{mg} \mathrm{L}^{-1}$ ) and rose up to $200 \mathrm{mg} \mathrm{L}^{-1}$ after 2011, when the operation of the scrubber was changed. This effect was due to the reduced water use in the new operation mode, which affected mainly the concentration while the bromide load remained almost stable (Figure S5b).

Annual bromide loads of these municipal waste incinerators were calculated by multiplying the average annual bromide concentration by the annual wastewater discharge. These calculated bromide loads are $30-50 \%$ lower than estimations from our mass flow analysis in Table S1. This is quite a small deviation considering the uncertainty of the mass flow analysis and of the calculated bromide loads of the municipal waste incinerators 1-3. The mass flow analysis is based on very few measurements of the bromine content of Swiss waste and of bromine fate upon incineration. Furthermore, bromide loads of municipal waste incinerators 1-3 are estimated from an annual wastewater discharge. Nevertheless, it should be noted that our mass flow analysis was rather conservative (no increase of BFRs content in the waste was considered for the last 10 years) but the resulting bromide discharges were still above the calculated discharges of municipal waste incinerators $1-3$.

Since wastewaters of municipal waste incinerators are discharged directly or indirectly (via WWTP) to surface waters, bromide loads from municipal waste incinerators to major rivers in Switzerland can be calculated (Table S2). It is estimated that $\sim 370 \mathrm{t} \mathrm{a}^{-1}$ bromide in the river Rhine at Weil am Rhein originate from burnt waste in municipal waste incinerators. 


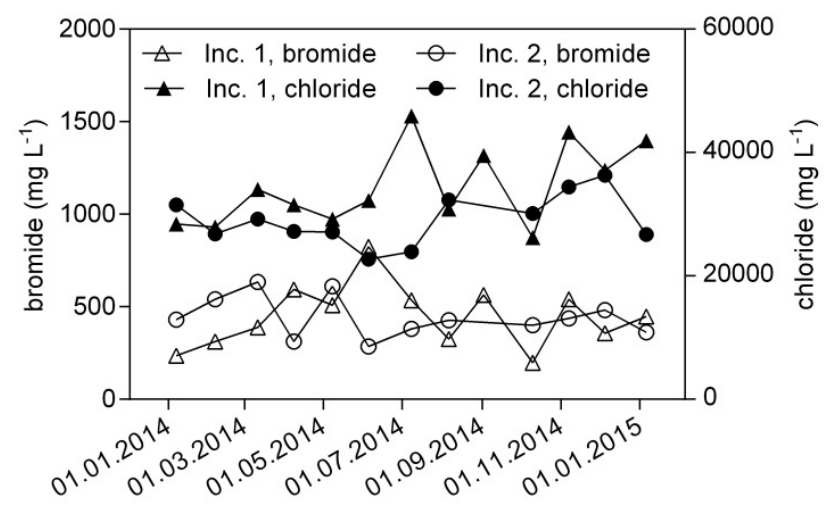

Figure S4: Bromide and chloride concentrations measured in monthly composite samples of waste water of two municipal waste incinerators (No 1, 2).
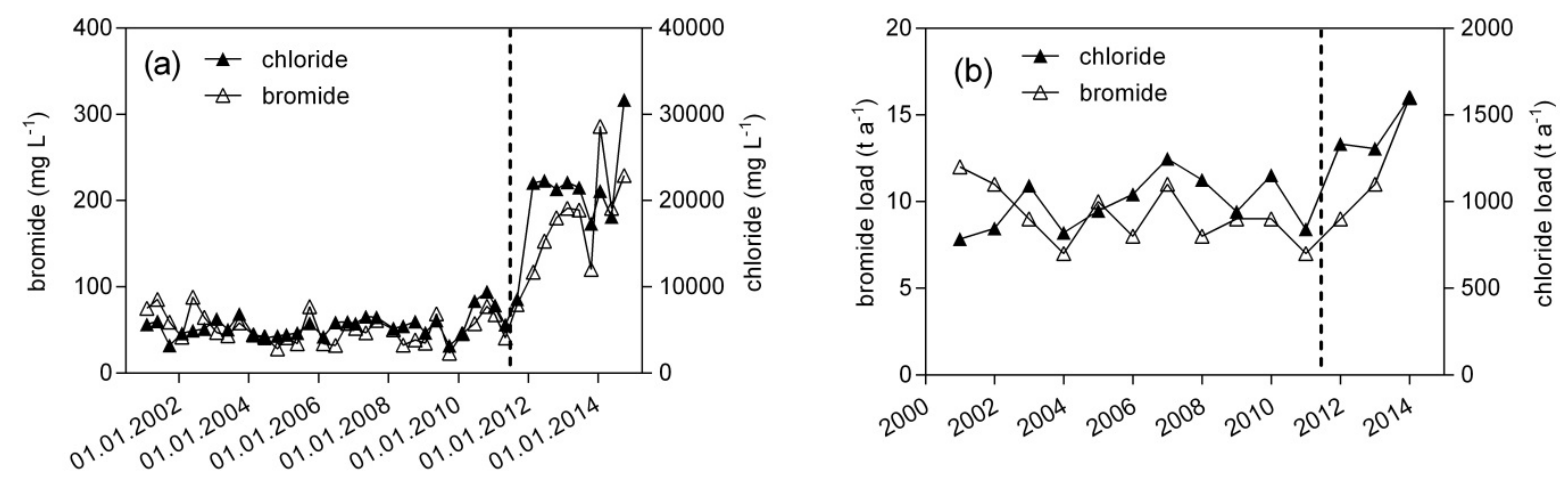

Figure S5: (a) Variation of bromide and chloride concentrations in daily composite samples of wastewater of municipal waste incinerator No 3 before and after changes in the scrubber operation in 2011 (dashed line). (b) Variation of bromide and chloride loads before and after changes in the scrubber operation in 2011 (dashed line). 


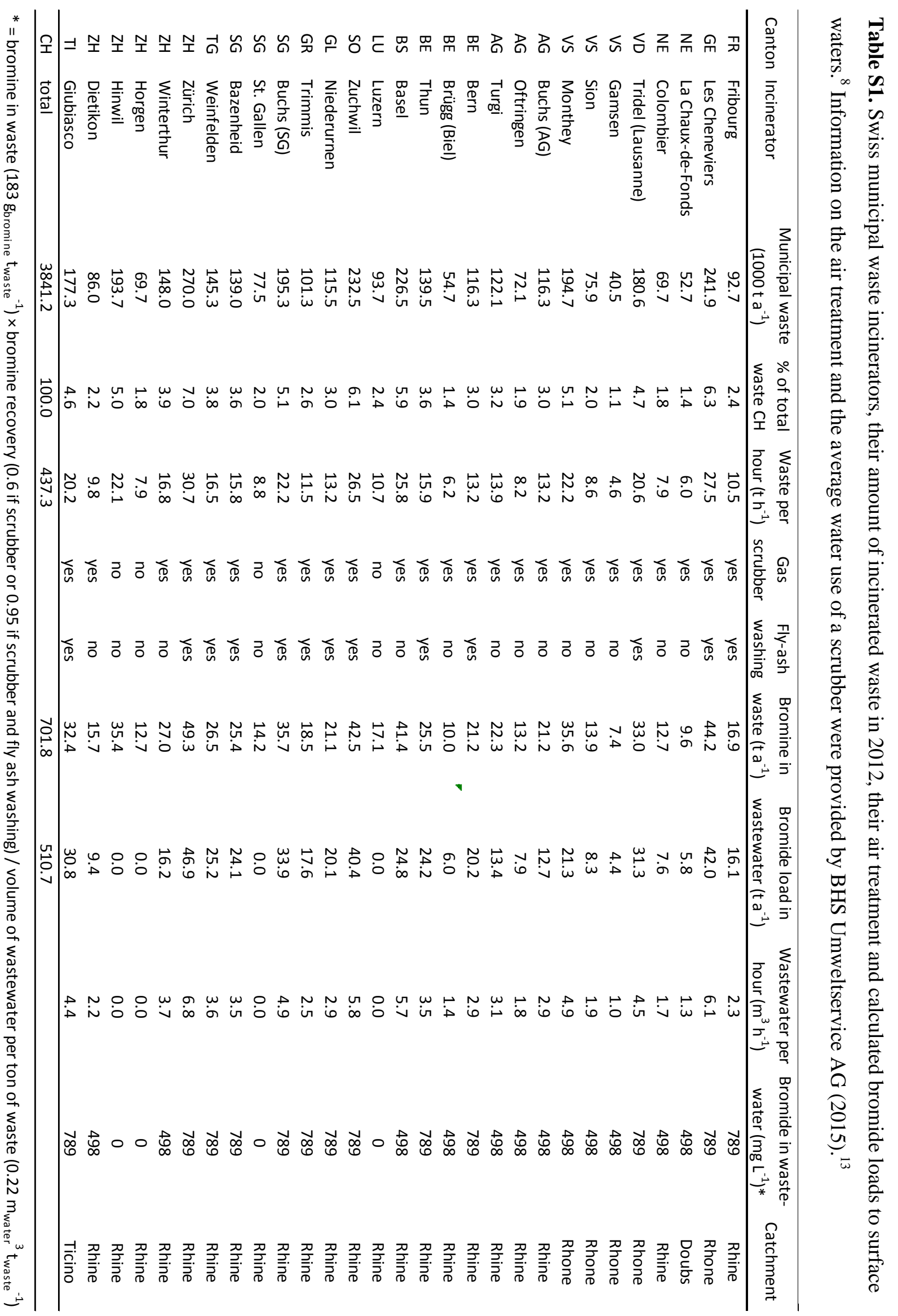


Table S2. Calculated bromide loads $\left(\mathrm{t}^{-1}\right)$ from Swiss municipal waste incinerators to major rivers in 2012.

\begin{tabular}{ccccc}
\hline & Rhine & Rhone & Doubs & Ticino \\
\hline $\begin{array}{c}\text { without increase of BFRs* } \\
\text { inclusive } 5 \% \mathrm{a}^{-1} \text { increase }\end{array}$ & 367 & 107 & 6 & 31 \\
$\begin{array}{c}\text { in BFRs content of waste } \\
\text { from 2002 to 2012 }\end{array}$ & 597 & 175 & 9 & 50 \\
\hline
\end{tabular}

*BFRs: brominated flame retardants

\section{Text S3.}

Agriculture. Methyl bromide was a popular pesticide worldwide until a reduction of the methyl bromide discharges was imposed by the amendments of the Montreal Protocol, after which a phaseout began in 1998. ${ }^{15}$ We assume that the application of methyl bromide does not contribute to current bromide loads in Swiss rivers. Methyl bromide is volatile and tracer experiments with bromide in agricultural soils showed that $50 \%$ of the applied bromide is washed out of a lysimeter within one year. ${ }^{16}$

A screening of more than 200 pesticides in Swiss surface waters revealed that there was no brominated pesticide among the 20 pesticides with the highest measured concentrations. ${ }^{17}$ Even if a pesticide is brominated, the bromine mass fraction in pesticides is usually low. The annual use of pesticides in Swiss agriculture was estimated to $\sim 1500 \mathrm{t}^{18}$ Therefore, we assume that pesticides used in agriculture do not significantly influence bromide concentration in Swiss surface waters.

A potential source of bromide in agriculture is the use of fertilizers (potassium or sodium bromide). The Swiss excess of imports of potassium and sodium during the last years was between 17 and $55 \mathrm{t} \mathrm{a}^{-1}$ (Table S3). ${ }^{19}$ The imported sodium bromide might also be partly used in the production of hypobromous acid for disinfection. As a consequence, the bromide load from agriculture to surface waters in Switzerland is assumed to be $<40 \mathrm{t} \mathrm{a}^{-1}\left(27 \mathrm{t} \mathrm{a}^{-1}, 11 \mathrm{t} \mathrm{a}^{-1}, 8 \mathrm{t} \mathrm{a}^{-1}\right.$ and $7 \mathrm{t} \mathrm{a}^{-1}$ for the catchments of Weil am Rhein, Brugg, Rekingen and Lake Geneva, respectively, according to their surfaces).

Table S3. Swiss excess of imports of sodium and potassium bromide from 2010-2014 (data from Swiss Federal Department of Finance $\left.(\mathrm{FDF})^{19}\right)$.

\begin{tabular}{lccccc}
\hline year & 2010 & 2011 & 2012 & 2013 & 2014 \\
\hline sodium and potassium bromide $(\mathrm{t})$ & 55 & 49 & 39 & 24 & 17 \\
\hline
\end{tabular}

Human input to wastewater. The human input of bromide to wastewater (by urine and sweat) was estimated to be 7-8 mg person ${ }^{-1} \mathrm{~d}^{-1} .^{20}$ The annual bromide load in Switzerland is therefore about $22 \mathrm{t} \mathrm{a}^{-1}$. According to the population in the catchment, human inputs result in bromide loads of $17 \mathrm{t} \mathrm{a}^{-1}, 7 \mathrm{t} \mathrm{a}^{-1}, 6 \mathrm{t} \mathrm{a}^{-}$ ${ }^{1}$ and $4 \mathrm{t} \mathrm{a}^{-1}$ for Weil am Rhein, Brugg, Rekingen and Lake Geneva, respectively. 
Landfills. Bromide is usually not monitored in the runoff of landfills in Switzerland, except for one landfill with special chemical waste where the annual bromide load in the runoff was constantly $\sim 10 \mathrm{t}$ during the last 15 years. ${ }^{21}$ There is a detailed monitoring for chloride in landfills of the canton of Zurich. ${ }^{22}$ Chloride concentrations in the runoff of landfills with inert waste were in the low $\mathrm{mg} \mathrm{L}^{-1}$ range, while landfills with slag or fly ash of municipal waste incinerators have chloride concentrations in the range of 1-10 $\mathrm{g} \mathrm{L}^{-1}$. The total chloride load in the runoff of landfills in the canton of Zurich was between 200 and $450 \mathrm{t} \mathrm{a}^{-1}$. The chloride-to-bromide $\left(\mathrm{Cl}^{-} / \mathrm{Br}^{-}\right)$ratio (mass) was measured in one landfill and was $\sim 100$ for two compartments containing slag of a municipal waste incinerator and $\sim 200$ in the reactor compartment. ${ }^{23}$ Therefore, the annual bromide load for the canton of Zurich is estimated at $2-4 \mathrm{t} \mathrm{a}^{-1}$. Since the canton of Zurich incinerates $~ 15 \%$ of the waste of Switzerland, total bromide discharge in Switzerland from incinerator slag and fly ash is estimated at $10-30 \mathrm{t} \mathrm{a}^{-1}$. Hence, we assume an annual bromide load of $\sim 25$ t from Swiss landfills with dumped fly ash or slag from municipal waste incinerators in our mass balance, which is at the upper range of our estimations. Furthermore, $\sim 10 \mathrm{t} \mathrm{a}^{-1}$ of bromide from the abovementioned specific chemical waste landfill (part of catchements Brugg and Weil am Rhein) are included in the mass balance. Sharing the bromide load of $25 \mathrm{t}$ proportionally to the population of the catchment and adding the bromide load from the chemical waste landfill results in annual bromide loads of 30 t, 18 t, 6 t and 4 t for Weil am Rhein, Brugg, Rekingen and Lake Geneva, respectively.

\section{Water disinfection in industry (e.g. steel, paper or food industry) and private swimming pools.}

The application of bromine-containing disinfectants usually leads to bromide. The use of brominecontaining disinfectants is not common in public pools but is still practiced in private pools. Exact figures regarding the amount of bromine-containing disinfectants used in Switzerland for pool water treatment are difficult to obtain. One specific product (bromochloro-5,5-dimethylimidazolidine-2,4-dione) has a high bromine content $(30 \% \mathrm{w} / \mathrm{w})$, other products are usually in the range of $5-10 \% \mathrm{w} / \mathrm{w}$. A major supplier in Switzerland sells about $12-14 \mathrm{t} \mathrm{a}^{-1}$ of the product with high bromine content which corresponds to a bromide load of $\sim 4-5 \mathrm{t} \mathrm{a}^{-1} .^{24}$

Bromine-containing biocides are also frequently used in the cooling water of open cooling systems in the steel, paper and food industry. To our knowledge, nuclear power plants in Switzerland do not use brominated products in their cooling systems. The annual bromide load in Switzerland from steel and paper industry is estimated to be about $20 \mathrm{t} \mathrm{a}^{-1} .{ }^{24}$ There is no information available for the food industry.

Therefore, the total load from bromine-containing disinfectants and biocides is estimated to $40-60 \mathrm{t} \mathrm{a}^{-1}$ for Switzerland. Assuming a distribution proportional to the population results in estimated bromide loads of $39 \mathrm{t} \mathrm{a}^{-1}, 16 \mathrm{t} \mathrm{a}^{-1}, 13 \mathrm{t} \mathrm{a}^{-1}$ and $8 \mathrm{t} \mathrm{a}^{-1}$ for Weil am Rhein, Brugg, Rekingen and Lake Geneva, respectively. 
Road and industrial salt. The average annual salt consumption in Switzerland was about 500'000 $\mathrm{t}$ in the period 2010-2014. The salt was mainly used as road salt ( 50\%) and in industry $(\sim 25 \%)$. ${ }^{25}$ More than $90 \%$ of the salt was produced in Switzerland and had a low bromide content (10-15 mg bromide $\left.\mathrm{kg}_{\text {salt }}{ }^{-1}\right){ }^{19,25}$ This results in an annual bromide load from salt of about $6 \mathrm{t} \mathrm{a}^{-1}$ for Switzerland and in bromide loads of $5 \mathrm{t}$ $\mathrm{a}^{-1}, 2 \mathrm{t} \mathrm{a}^{-1}, 2 \mathrm{t} \mathrm{a}^{-1}$ and $1 \mathrm{t} \mathrm{a}^{-1}$ for the catchments of Weil am Rhein, Brugg, Rekingen and Lake Geneva, respectively.

Mineral springs. Major mineral springs of Switzerland used for drinking water production and for thermal baths are located in the canton of Aargau. The total mineral water output of these springs is around 5’000 $\mathrm{L} \mathrm{s}^{-1}{ }^{26}$ There are various other mineral springs in Switzerland which are mainly used for drinking water production. Bromide in drinking water is already considered in the bromide mass balance from human input (see this section). Therefore, these springs are not taken into account. Bromide concentrations in Swiss mineral water vary form $<0.5 \mu \mathrm{g} \mathrm{L}{ }^{-1}$ to $760 \mu \mathrm{g} \mathrm{L}{ }^{-1} \cdot{ }^{27}$ Assuming the highest bromide content and a complete use of the mineral water from the canton of Aargau for bathing results in a bromide load of $\sim 2 \mathrm{t}$ $\mathrm{a}^{-1}$ from mineral springs. This source is not taken into account for the catchments Brugg and Rekingen.

Import from Germany and Austria. A minor part of the catchment of the Rhine river at Rekingen and Weil am Rhein is located in Germany and Austria. The category "precipitation and geogenic” sources already accounts for water from these areas. All other categories do not consider sources in Germany and Austria. Since the sampling station at Rekingen, where low bromide loads were measured, includes most of the subcatchment in Austria and and Germany, it can be assumed that bromide loads from these areas are minor. Gilfedder et al. ${ }^{28}$ determined the bromide load from Germany and Austria in the catchment of Lake Constance. In 2005, about 3'000 million $\mathrm{m}^{3}$ water with a load of $75 \mathrm{t}$ bromide (85 $\mathrm{t}$ of total dissolved bromine (bromide plus organically bound bromine)) fed Lake Constance from Germany and Austria. Since $15 \mathrm{t}$ (5 $\mu \mathrm{g} \mathrm{L}^{-1}$ bromide from precipitation and geogenic sources in the outflow at Weil am Rhein) are already considered in the mass balance, it is assumed that anthropogenic sources in German and Austrian subcatchments contribute about $60 \mathrm{t} \mathrm{a}^{-1}$. This bromide load affects bromide concentrations at Weil am Rhein and Rekingen, but not Brugg and Lake Geneva. 


\section{E Bromide sources from chemical and special waste industries}

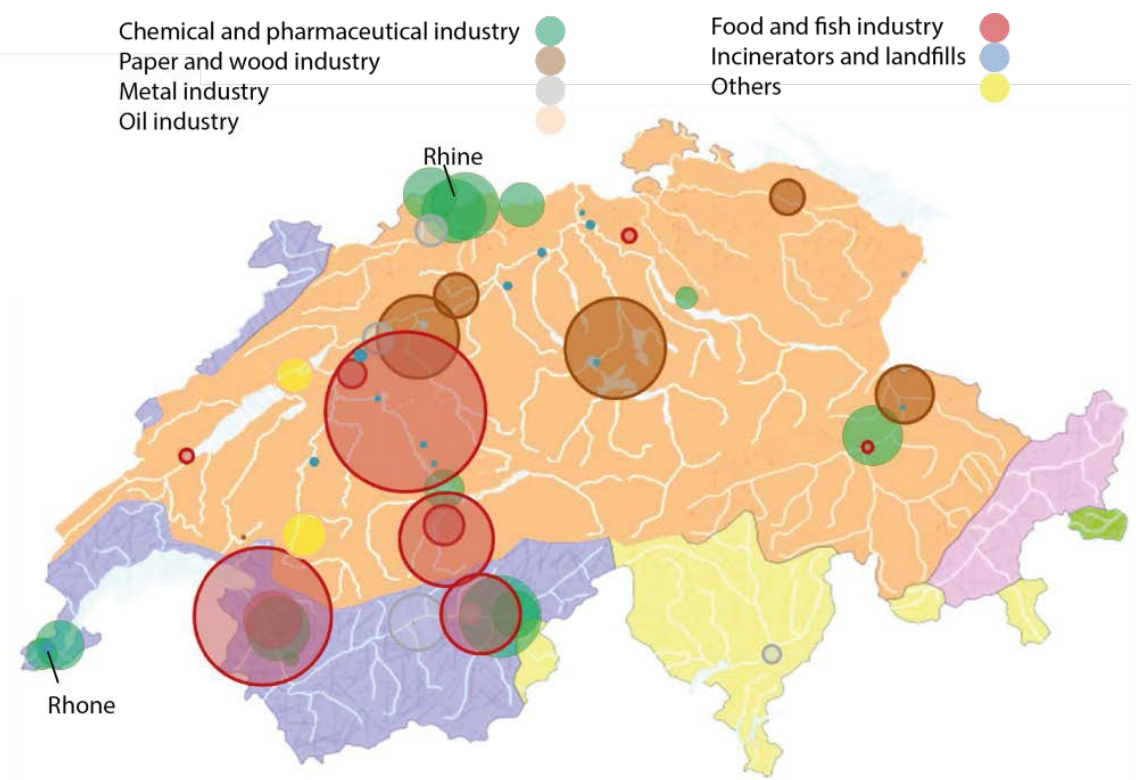

Figure S6: A survey on Swiss industries discharging micropollutants directly to surface waters (Figure from Braun and Gälli ${ }^{29}$, reproduced with permission from Swiss Federal Office for the Environment). The size of the circles corresponds to the volume of wastewater discharged (biggest circle $=12.8$ million $\mathrm{m}^{3}$ $\left.\mathrm{a}^{-1}\right)$. Colored areas correspond to catchments of major Swiss rivers. 

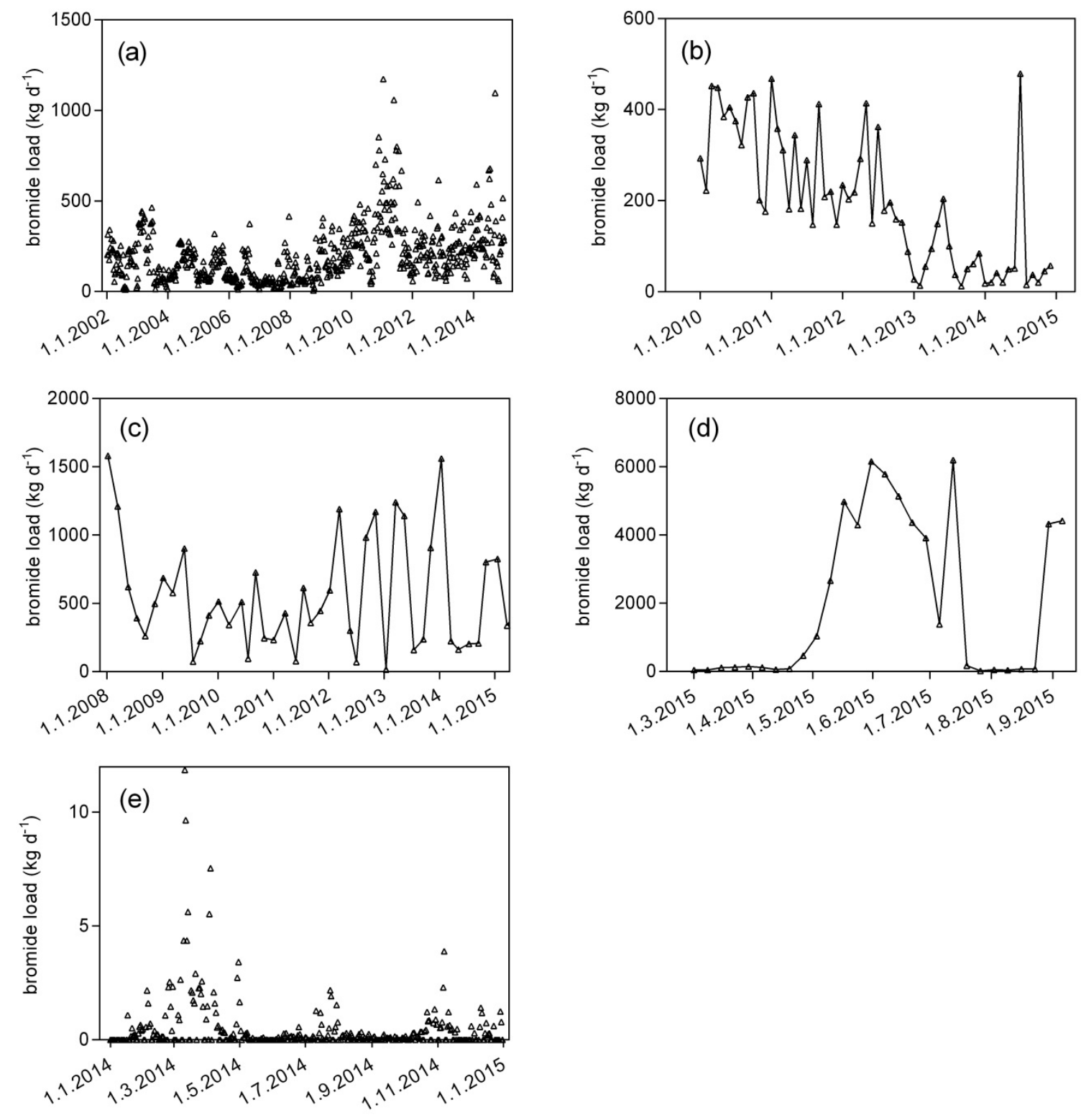

Figure S7: Daily bromide loads in (a-d) wastewaters from 4 industrial WWTPs with exclusively chemical industry in the catchment and (e) in the wastewater of a chemical production site. Daily loads were derived from weekly composite samples (a and d), monthly composite samples (b) and daily composite samples (c and e). WWTPs (a) and (c) are located in the catchment of Lake Geneva, WWTPs (b) and (d) in the catchment of Weil am Rhein and WWTP (e) in the catchments Brugg and Weil am Rhein. Bromide loads show high short- and long-term variations. 


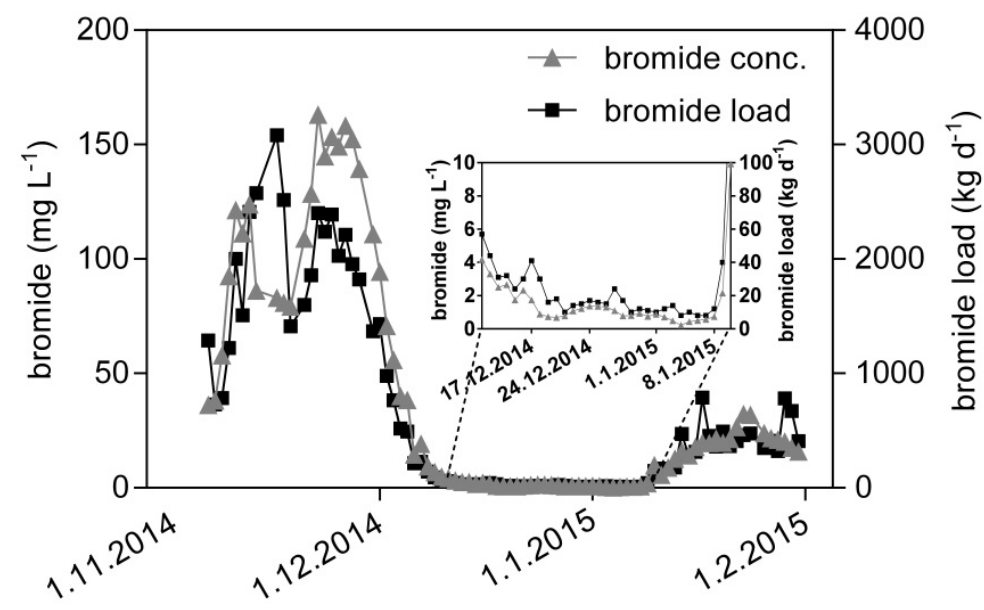

Figure S8: Bromide concentrations and loads in the effluent of a WWTP (catchment Brugg) were measured by daily composite samples (stored at $-20{ }^{\circ} \mathrm{C}$ and filtered directly before the analysis). The WWTP has a major chemical production site in the catchment. The bromide concentrations in the effluent dropped significantly over Christmas and New Year. The average concentrations over the entire period and the entire period without Christmas/New Year break (19.12.2014 - 9.1.2015) were 39.7 and $51.5 \mathrm{mg}$ $\mathrm{L}^{-1}$, respectively. To estimate an annual bromide load from the chemical industry in this catchment, the average bromide load of the sampling period except the Christmas/New Year break (884 $\mathrm{kg} \mathrm{d}^{-1}$ ) was extrapolated to one year. The resulting bromide load of $\sim 320 \mathrm{t} \mathrm{a}^{-1}$ is just a rough estimate because bromide loads vary strongly with production patterns. Furthermore, it must be considered that a municipal waste incinerator is located in the catchment of the WWTP, which might contribute 8 t to the annual bromide load. The incinerator is assumed to be the reason why bromide concentrations did not drop below a level of 500-700 $\mu \mathrm{g} \mathrm{L}^{-1}$ between Christmas and New Year. This level is similar to other WWTPs with municipal waste incinerators in their catchments. 

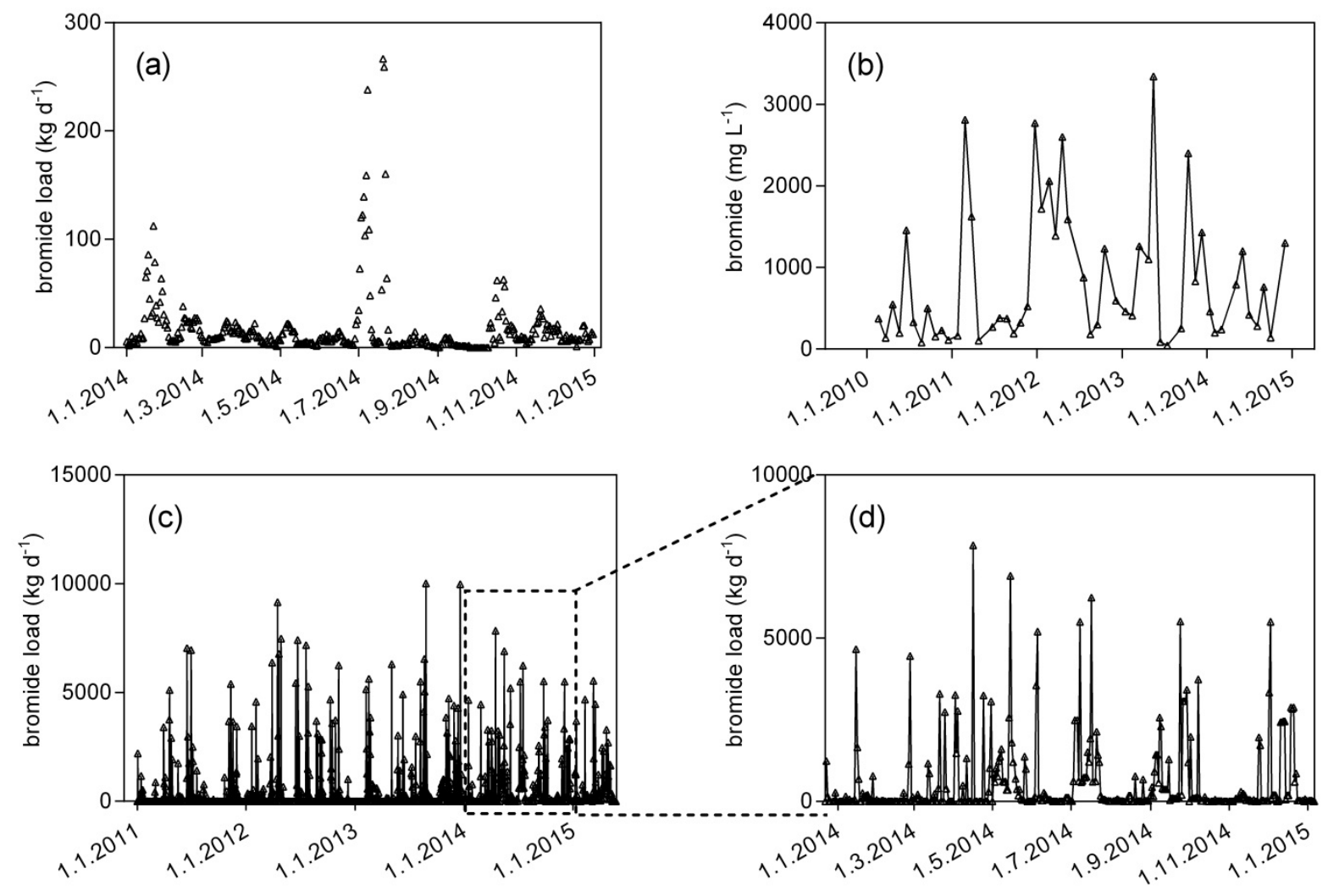

Figure S9: (a) Bromide loads from a special waste incinerator calculated from daily composite samples. (b) Bromide concentrations in wastewater from another special waste incinerator (one daily composite sample per month). The annual bromide loads were estimated by multiplying the annual wastewater discharges with the average bromide concentrations. (c, d) Bromide loads in daily released batches of a special liquid waste company, which also washes fly ash from municipal waste incinerators.

\section{Text S4.}

The union of Swiss waste utilization plants provides a list with 16 companies treating special waste, of which 6 are special waste incinerators (one special waste incinerator is located in Switzerland but outside the four investigated catchments). The mass balances are based on measured bromide discharges of all 5 special waste incinerators which are located within the boundaries of the four catchments.

Data of the other 10 companies treating special waste are scarce. Only one company treating liquid waste provided data on bromide discharges (Figures S9a, b). Investigation of the other companies revealed that many of them are not supposed to discharge bromide to surface water or wastewater because either they only separate, recycle or transfer special waste, or they perform treatments with no discharge of liquid waste. Nevertheless, the uncertainty of bromide discharges from these companies is high. 


\section{F Bromide in Lake Geneva}

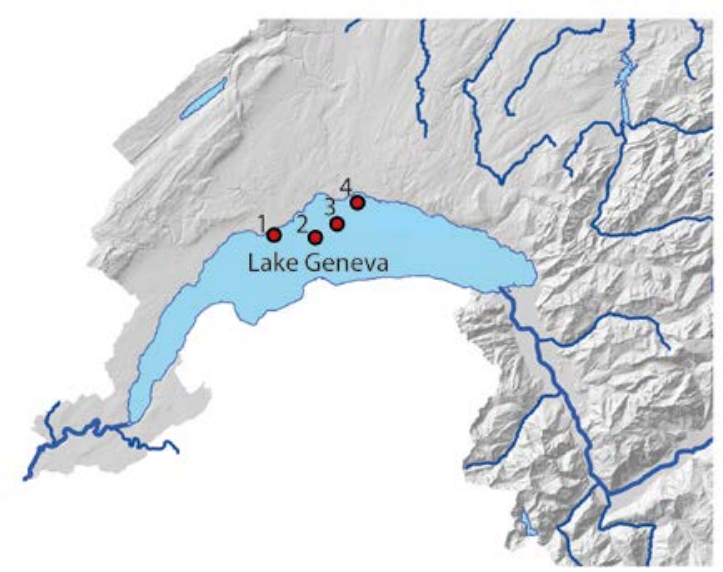

Figure S10: Sampling positions for bromide measurements in Lake Geneva at $0.5 \mathrm{~m}$ (positions 3 and 4) and $30 \mathrm{~m}$ (positions 1-4) depth. Map reproduced with permission from (C) swisstopo, Wabern, Switzerland.

Table S4. Bromide concentrations measured in Lake Geneva at 4 positions (Figure S10) and at $0.5 \mathrm{~m}$ and $30 \mathrm{~m}$ depth (in the epilimnion and hypolimnion, respectively). As assumed for non-reactive species in a mixed waterbody, bromide concentration were constant $\left(49 \pm 5 \mu \mathrm{g} \mathrm{L}^{-1}\right)$.

\begin{tabular}{ccc}
\hline position & depth $(\mathrm{m})$ & bromide $\left(\mu \mathrm{g} \mathrm{L}^{-1}\right)$ \\
\hline 1 & 30 & $49 \pm 5$ \\
2 & 30 & $50 \pm 5$ \\
3 & 0.5 & $49 \pm 5$ \\
3 & 30 & $49 \pm 5$ \\
4 & 0.5 & $49 \pm 5$ \\
4 & 30 & $49 \pm 5$ \\
\hline
\end{tabular}




\section{G Chloride-to-bromide ratios of waters from different sources}

\section{Text S5.}

Chloride concentrations are usually higher than bromide concentrations in surface water, groundwater and

wastewater. ${ }^{30}$ Chloride-to-bromide $\left(\mathrm{Cl}^{-} / \mathrm{Br}\right)$ ratios are often used as fingerprints to determine the origin or the composition of groundwater in hydrology. ${ }^{31}$ Furthermore, constant $\mathrm{Cl}^{-} / \mathrm{Br}^{-}$ratios would allow for monitoring water sources for high bromide concentrations by measuring chloride concentration or even conductivity. To investigate whether this is a reasonable approach for Swiss surface waters and/or wastewaters, $\mathrm{Cl}^{-} / \mathrm{Br}^{-}$mass ratios were determined for major bromide and chloride sources and compared to measured ratios in surface waters (Figure S11). Figure S11 reveals that the $\mathrm{Cl}^{-} / \mathrm{Br}^{-}$mass ratio in river Rhine at Rekingen $(877 \pm 182)$ is higher than at the two other sampling sites at Brugg $(122 \pm 160)$ and Weil am Rhein (172 \pm 82 ). This is probably because there are few anthropogenic bromide sources in the catchment of Rekingen. Major bromide sources (incinerators, chemical industry and special waste industry) usually have lower $\mathrm{Cl}^{-} / \mathrm{Br}^{-}$ratios. However, these ratios vary strongly with time especially in wastewater from chemical and special waste industry (Figure S11). Major chloride sources are probalby road or industrial salts which originate from Swiss salines and are poor on bromide $\left(\mathrm{Cl}^{-} / \mathrm{Br}^{-}\right.$mass ratio of 40’000). In conclusion, $\mathrm{Cl}^{-} / \mathrm{Br}^{-}$ratios are an inappropriate measure to determine the origin of water if important bromide sources such as chemical industry or special waste incinerators are in the catchment, because they release bromide with high temporal variability. To measure chloride or conductivity to conclude on bromide concentrations might also be misleading since the main chloride sources do not contain bromide and important bromide sources do not have constant $\mathrm{Cl}^{-} / \mathrm{Br}^{-}$ratios. 


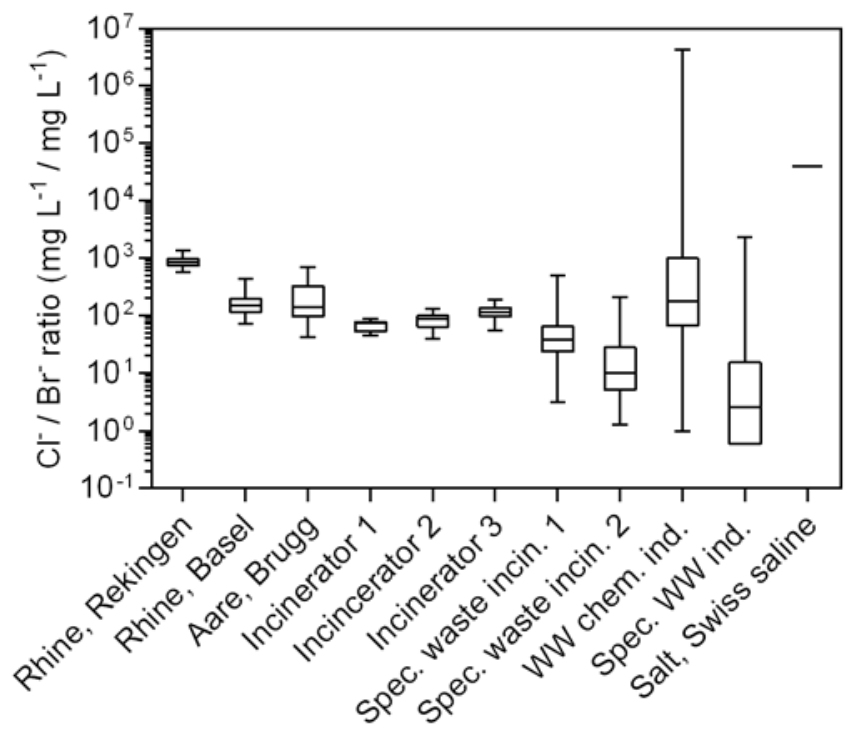

Figure S11: Chloride / bromide mass ratios measured in two rivers (Rhine and Aare) (biweekly composite samples over 4 years), three incinerators (monthly composite sample over 1 year (1+2) and 42 daily composite samples over 14 years (3)), two special waste incinerators (daily composite samples over one year (1) and monthly composite samples over 3 years (2)), in wastewater of a chemical production site (daily composite samples over one year), special wastewater industry (daily composite samples over 4 years) and in salt from a major Swiss saline (supplier information). 


\section{H Chemicals used in this study, analytical methods and detection limits of chloride, bromide and bromate measurements provided by industrial companies and authorities}

Text S6.

Bromide, bromate and chloride were purchased from Sigma-Aldrich. Sodium hydroxide (NaOH) pellets and hydrochloric acid ( $\mathrm{HCl})$ were obtained from Merck. Ultrapurified water was produced by a "barnstead nanopure” water purification system (Thermo Scientific).

Table S5. Analytical methods and detection limits for bromide and chloride measurements presented in the main text. Data provided by industrial or public partners are shown in italics.

\begin{tabular}{|c|c|c|c|c|c|}
\hline Data & Name & Compound & Device & Method & $\mathrm{LOQ}\left(\mathrm{mg} \mathrm{L}^{-1}\right)$ \\
\hline Figure $1+2$ & Rhine and Aare & bromide / chloride & Dionex 2000 & $\begin{array}{l}\text { DIN EN ISO } 10304 \\
\text { and } 3845-19\end{array}$ & $0.01 / 1.5$ \\
\hline \multirow[t]{8}{*}{ Figure 3a } & WWTP 1 & bromide & ICS 1100, Dionex AG & DIN EN ISO 10304 & 0.01 \\
\hline & WWTP 2 & bromide & ICS 1100, Dionex AG & DIN EN ISO 10304 & 0.01 \\
\hline & WWTP 3 & bromide & ICS 1100, Dionex AG & DIN EN ISO 10304 & 0.01 \\
\hline & WWTP 4 & bromide & ICS 1100, Dionex AG & DIN EN ISO 10304 & 0.01 \\
\hline & WWTP 5 & bromide & ICS 1100, Dionex AG & DIN EN ISO 10304 & 0.01 \\
\hline & WWTP 6 & bromide & ICS 1100, Dionex AG & DIN EN ISO 10304 & 0.01 \\
\hline & WWTP 7 & bromide & Compact IC pro, Metrohm & conductivity measurement & 0.002 \\
\hline & WWTP 8 & bromide & not specified & & \\
\hline \multirow[t]{2}{*}{ Figure 3b } & WWTP 1-70 & bromide & ICS 4000, Dionex AG & conductivity measurement & 0.01 \\
\hline & WWTP 1-70 & chloride & 761 compact, Metrohm & conductivity measurement & 0.5 \\
\hline \multirow[t]{6}{*}{ Figure 4} & WWTP A and B & bromide & ICS 3000, Dionex AG & conductivity measurement & 0.01 \\
\hline & WWTP A and B & bromate & ICS 3000, Dionex AG & $\begin{array}{l}\text { post-column reaction, } \\
\text { UV detector }\end{array}$ & 0.002 \\
\hline & WWTP C & bromide & Compact IC pro, Metrohm & conductivity measurement & 0.002 \\
\hline & WWTP C & bromate & Compact IC pro, Metrohm & $\begin{array}{l}\text { post-column reaction (iodid), } \\
\text { UV detector }\end{array}$ & 0.0006 \\
\hline & WWTP D & bromide / bromate & ICS 1100, Dionex AG & DIN EN ISO 10304 & 0.01 \\
\hline & WWTP E & bromide / bromate & ICS 1100, Dionex AG & DIN EN ISO 10304 & 0.01 \\
\hline
\end{tabular}


Table S6. Analytical methods and detection limits for bromide and chloride measurements presented in the Supporting Information. Data provided by industrial or public partners are shown in italics.

\begin{tabular}{|c|c|c|c|c|c|}
\hline Data & Name & Compound & Device & Methode & $\operatorname{LOQ}\left(\mathrm{mg} \mathrm{L}^{-1}\right)$ \\
\hline Figure S.3. & Weil am Rhein & bromide/chloride & Dionex 2000 & DIN EN ISO 10304国nd 3845- & $-0.01 / 1.5$ \\
\hline \multirow[t]{2}{*}{ Figure S.4. } & Incinerator 1 & bromide/chloride & 850 Professional IC, Metrohm & DIN EN ISO 10304 & $0.01 / 0.1$ \\
\hline & Incinerator 2 & bromide/chloride & 850 Professional IC, Metrohm & DIN EN ISO 10304 & $0.01 / 0.1$ \\
\hline Figure S.5. & Incinerator & bromide/chloride & $I C$, not defined & DIN EN ISO 10304 & $0.5 / 0.1$ \\
\hline \multirow[t]{6}{*}{ Figure S.7. } & Chemical industry $a$ & bromide & not specified & not specified & 0.05 \\
\hline & Chemical industry $b$ & bromide & Dionex ICS3000, Thermo Fisher & DIN EN ISO 10304 & 10 \\
\hline & Chemical industry $b$ & chloride & 877 Titrino plus, Metrom & argentometry & 1 \\
\hline & Chemical industry $c$ & bromide & ICS 1100, Dionex AG & DIN EN ISO 10304 & 1 \\
\hline & Chemical industry d & bromide & ICS 1100, Dionex AG & not specified & 0.1 \\
\hline & Chemical industrye & bromide & not specified & not specified & not specified \\
\hline Figure S.8. & WWTP & bromide & ICS 4000, Dionex AG & conductivity measurement & 0.01 \\
\hline \multirow[t]{3}{*}{ Figure S.9. } & Special waste inc. a & bromide & ICS 1100, Dionex AG & not specified & 0.1 \\
\hline & Special waste inc. $b$ & bromide & not specified & not specified & not specified \\
\hline & Special waste ind. $c-d$ & bromide & Compact IC pro, Metrohm & DIN EN ISO 10304 & 0.4 \\
\hline Figure S.10. & Lake Geneva & bromide & ICS 4000, Dionex AG & conductivity measurement & 0.01 \\
\hline \multirow[t]{7}{*}{ Figure S.11. } & Incinerator 1 & bromide / chloride & 850 Professional IC, Metrohm & DIN EN ISO 10304 & $0.01 / 0.1$ \\
\hline & Incinerator 2 & bromide / chloride & 850 Professional IC, Metrohm & DIN EN ISO 10304 & $0.01 / 0.1$ \\
\hline & Incinerator 3 & bromide / chloride & IC, not specified & DIN EN ISO 10304 & $0.5 / 0.1$ \\
\hline & Special waste incinerator 1 & bromide / chloride & ICS 1100, Dionex AG & not specified & 0.1 \\
\hline & Special waste incinerator 2 & bromide / chloride & not specified & not specified & not specified \\
\hline & Chemical industry & bromide / chloride & ICS 1100, Dionex AG & not specified & 0.1 \\
\hline & Special waster industry & bromide / chloride & Compact IC pro, Metrohm & DIN EN ISO 10304 & 0.4 \\
\hline
\end{tabular}

Table S7. Ozone generators and methods for DOC measurement used for bromate formation experiments.

\begin{tabular}{|c|c|c|c|c|c|}
\hline Data & Name & Compound & Device / Generator & Methode & LOQ \\
\hline \multirow[t]{10}{*}{ Figure 4} & WWTP A & DOC & TOC-L CSH, Shimadzu & $\mathrm{CO}_{2}$ measurement & $0.5 \mathrm{mg} \mathrm{C} \mathrm{L}^{-1}$ \\
\hline & & ozone & CMG 3-3 & UV direct (stock solution) & $10 \mathrm{mM}$ \\
\hline & WWTP B & DOC & TOC-L CSH, Shimadzu & $\mathrm{CO}_{2}$ measurement & $0.5 \mathrm{mg} \mathrm{C} \mathrm{L}^{-1}$ \\
\hline & & ozone & CMG 3-3 & UV direct (stock solution) & $10 \mathrm{mM}$ \\
\hline & WWTP C & DOC & TOC-L CPH, Shimadzu & $\mathrm{CO}_{2}$ measurement, infrared & $0.09 \mathrm{mg} \mathrm{C} \mathrm{L}^{-1}$ \\
\hline & & ozone & ozone generator not defined & Indigo method & not specified \\
\hline & WWTP D & $\mathrm{DOC}$ & $\begin{array}{l}\text { DIMATOC 2000, } \\
\text { Dimatec Analysentechnik GmbH }\end{array}$ & $\mathrm{CO}_{2}$ measurement, infrared & $0.1 \mathrm{mg} \mathrm{C} \mathrm{L}^{-1}$ \\
\hline & & ozone & ozone generator not defined & Indigo method & $0.6 \mathrm{mM}$ \\
\hline & WWTP E & $\mathrm{DOC}$ & $\begin{array}{l}\text { DIMATOC 2000, } \\
\text { Dimatec Analysentechnik GmbH }\end{array}$ & $\mathrm{CO}_{2}$ measurement, infrared & $0.1 \mathrm{mg} \mathrm{C} \mathrm{L}^{-1}$ \\
\hline & & ozone & ozone generator not defined & Indigo method & $0.6 \mathrm{mM}$ \\
\hline
\end{tabular}




\section{References}

1. $\quad$ Eggen, R. I. L.; Hollender, J.; Joss, A.; Schärer, M.; Stamm, C., Reducing the Discharge of Micropollutants in the Aquatic Environment: The Benefits of Upgrading Wastewater Treatment Plants. Environ. Sci. Technol. 2014, 48, (14), 7683-7689.

2. $\quad$ Federal Office for the Environment (FOEN), Erläutender Bericht zur Änderung der Gewässerschutzverordnung; 2014.

3. Abegglen, C.; Siegrist, H., Mikroverunreinigungen aus kommunalem Abwasser; Federal Office for the Environment (FOEN), Bern.: 2012.

4. $\quad$ Schindler Wildhaber, Y.; Mestankova, H.; Schärer, M.; Schirmer, K.; Salhi, E.; von Gunten, U., Novel test procedure to evaluate the treatability of wastewater with ozone. Water Research 2015, 75, (0), 324-335.

5. $\quad$ von Gunten, U.; Salhi, E., Bromate in Drinking Water A problem in Switzerland? Ozone: Science \& Engineering 2003, 25, (3), 159-166.

6. Birnbaum, L. S.; Staskal, D. F., Brominated flame retardants: cause for concern? Environ. Health Perspect. 2004, 112, (1), 9.

7. $\quad$ Morf, L.; Taverna, R.; Daxbeck, H.; Smutny, R., Ausgewählte polybromierte Flammschutzmittel Stoffflussanalyse; Federal Office for the Environment (FOEN), Bern.: 2002.

8. $\quad$ Federal Office for the Environment (FOEN): Brennbare Abfälle in KVA 2012. http://www.bafu.admin.ch/abfall/01517/01519/12949/index.html?lang=en (last retrieved 1.8.2016).

9. Cemsuisse: Brennstoffe. http://www.cemsuisse.ch/cemsuisse/produktion/brennstoffe/index.html?lang=de (last retrieved 1.8.2016).

10. Morf, L. S.; Schenk, K.; Fahrni, H.-P., Chemische Zusammensetzung verbrannter Siedlungsabfälle. Müll und Abfall 2007, 4, (07), 169-175.

11. Steiger, U., Erhebung der Kehrichtzusammensetzung 2012; Federal Office for the Environment (FOEN), Bern.: 2014.

12. Belevi, H.; Moench, H., Factors determining the element behavior in municipal solid waste incinerators. 1. Field studies. Environ. Sci. Technol. 2000, 34, (12), 2501-2506.

13. BHS Umweltservice AG, personal communication (2015).

14. Federal Office for the Environment (FOEN), Abwässer aus Kehrichtverbrennungsanlagen; 2004; pp 5423-5432.

15. Yvon-Lewis, S.; Saltzman, E.; Montzka, S., Recent trends in atmospheric methyl bromide: analysis of post-Montreal Protocol variability. Atmospheric Chemistry and Physics 2009, 9, (16), 59635974.

16. Prasuhn, V.; Christiane, V. A., Grundwasserqualität und Bewässerung. Aqua und Gas 2014, 4, 5458. 
17. Moschet, C.; Wittmer, I.; Simovic, J.; Junghans, M.; Piazzoli, A.; Singer, H.; Stamm, C.; Leu, C.; Hollender, J., How a Complete Pesticide Screening Changes the Assessment of Surface Water Quality. Environ. Sci. Technol. 2014, 48, (10), 5423-5432.

18. Gerecke, A. C.; Schärer, M.; Singer, H. P.; Müller, S. R.; Schwarzenbach, R. P.; Sägesser, M.; Ochsenbein, U.; Popow, G., Sources of pesticides in surface waters in Switzerland: pesticide load through waste water treatment plants—current situation and reduction potential. Chemosphere 2002, 48, (3), 307315.

19. Swiss Federal Department of Finance (FDF): Swiss-Impex. https://www.swiss-impex.admin.ch/ (last retrieved 1.8.2016).

20. Koppe, P.; Stozek, A., Kommunales Abwasser: seine Inhaltsstoffe nach Herkunft, Zusammensetzung und Reaktionen im Reinigungsprozeß einschließlich Klärschlämme. Vulkan-Verlag GmbH: 1999.

21. Geschäftsstelle Sondermülldeponie Kölliken (SMDK): Jahresbericht 2013. http://www.smdk.ch/index.cfm?action=act getfile\&doc id=102513 (last retrieved 1.8.2016).

22. Office of Waste, Water, Energy and Air of canton Zurich (WWEA): Deponiestatistik 2013. http://www.awel.zh.ch/content/dam/baudirektion/awel/abfall_rohstoffe_altlasten/abfall/dokumente/statisti ken/deponie_statistiken/deponiestatistik_2013.pdf (last retrieved 1.8.2016).

23. Matzke, H. Von laufendem Betrieb in die Nachsorge, unpublished. Presentation at "2. Nationaler Deponietagung, Olten", 20.3.2015.

24. Anonymous, personal communication (2015).

25. Schweizer Salinen AG: Schweizer Salinen. http://www.salz.ch (last retrieved 1.8.2016).

26. Burger, H., Vorkommen, Nutzung und Schutz von Thermalwässern und Mineralwässern im Kanton Aargau: eine Übersicht. Swiss Bull. angew. Geol. 2009, 14, (1+2), $13-27$.

27. Verband Schweizerischer Mineralquellen und Softdrink Produzenten: Mineralisierungstabelle Schweiz. http://mineralwasser.ch/wp-content/uploads/sites/3/2015/04/mineralisierungstabelle.pdf (last retrieved 1.8.2016).

28. Gilfedder, B. S.; Petri, M.; Wessels, M.; Biester, H., Bromine species fluxes from Lake Constance's catchment, and a preliminary lake mass balance. Geochimica et Cosmochimica Acta 2011, 75, (12), 3385-3401.

29. Braun, C.; Gälli, R., Mikroverunreinigungen aus Industrie und Gewerbe. Erste Grundlagenerhebung mittels Umfrage bei den Kantonen zu vorhandenen Informationen.; BMG Engineering AG on behalf of Federal Office for the Environment (FOEN): 2014.

30. Winid, B., Bromine and water quality - Selected aspects and future perspectives. Applied Geochemistry 2015, 63, 413-435.

31. Davis, S. N.; Whittemore, D. O.; Fabryka-Martin, J., Uses of chloride/bromide ratios in studies of potable water. Groundwater 1998, 36, (2), 338-350. 